Research Article

\title{
Study on Mechanical and Ecological Properties of Fly Ash Substrate for Ecological Slope Protection
}

\author{
Juan Wan, Jun Zhu (D), Henglin Xiao $\mathbb{D}$, and Qiang Ma $(\mathbb{D}$ \\ Hubei University of Technology, Hubei Provincial Ecological Road Engineering Technology Research Center, \\ Wuhan 430068, China \\ Correspondence should be addressed to Henglin Xiao; xiao-henglin@163.com
}

Received 25 March 2019; Revised 22 May 2019; Accepted 28 May 2019; Published 18 June 2019

Academic Editor: Castorina S. Vieira

Copyright (c) 2019 Juan Wan et al. This is an open access article distributed under the Creative Commons Attribution License, which permits unrestricted use, distribution, and reproduction in any medium, provided the original work is properly cited.

In order to realize the resource utilization of fly ash, a kind of ecological slope protection substrate was prepared by mixing fly ash produced by MSW incineration into slope protection soil. Through the direct shear test and a leaching experiment on ion pollutants, the influence that shear strength of the substrate changed with root content, ash content, and moisture content and the ecological effects of leach liquor were investigated. The results showed the following: (1) When the optimum moisture content is about $24.9 \%$, the shear strength of the substrate is the maximum. (2) Fly ash can improve the shear strength of the soil, which can reach 1.67 times as much as that of plain soil, and the optimum content of fly ash is 5\%-6.7\%. (3) The root system can increase the cohesion and internal friction angle of the substrate soil but mainly increases the cohesion of the substrate soil. (4) Plants grow taller in ash-mixed soil than in plain soil. (5) When the fly ash content is $20 \%$, the ion concentrations of $\mathrm{Cl}, \mathrm{Cu}$, and $\mathrm{Zn}$ are the highest: $220.7,0.153$, and $1.526 \mathrm{mg} / \mathrm{L}$, respectively. All of them are lower than the standard limit of class $\mathrm{V}$ water and gradually decrease with time. Therefore, the leaching liquid will not cause environmental pollution and meet the ecological requirements.

\section{Introduction}

In the process of urbanization, the amount of domestic garbage, which is a product of urban metabolism, continues to rise. Eventually, if its treatment is not timely, it will critically restrict urban development and cause grave harm to the urban ecological environment [1-4]. Waste incineration in thermal power plants is an effective way of municipal solid waste treatment widely used all over the world at present, which can save land resources and make the best of energy $[3,5,6]$. However, fly ash can be produced in waste incineration, If it is not treated properly, it will inevitably result in waste of resources and pollution of natural environmental, thus affecting people's lives. Therefore, in the context of the energy and environmental crises, the resource utilization of fly ash from refuse incineration is of considerable significance to human health and ecological environment [4-9].

Scholars at home and abroad have made some study on converting fly ash from garbage incineration into useful materials for engineering. Many researchers have found that the addition of fly ash to soil is beneficial to plant growth, and soil improvements fly ash that is full of phosphorus, potassium, and calcium will trigger a series of biological reactions when mixed with soil. Bierman and Rosen [10], Ray Sarkar et al. [11], and Singh et al. [12] have found that fly ash added into the soil can increase essential plant elements, such as $\mathrm{N}, \mathrm{P}, \mathrm{K}$, and $\mathrm{Si}$, which promote plant growth. Wang et al. have found that it is feasible to use fly ash to improve acid soil [13]. Yang et al. have found that heavy elements metals, such as $\mathrm{Pb}, \mathrm{Cd}, \mathrm{Cu}$, and $\mathrm{Zn}$, contained in fly ash can be reduced by certain special physiological plant functions (such as absorption, degradation, stabilization, and volatilization) [14].

The inclusion of waste incineration fly ash in slope protection soil can convert it into a beneficial material; however, the incorporation of fly ash changes the strength properties of the soil. In order to prevent early soil erosions and shallow landslides, it is extremely important to improve the shear strength of soil employed in ecological slope 
protection engineering. Nowadays, mixing a certain amount of cement with soil is a typical method of improving soil strength, which is agreed and adopted by many scholars both at home and abroad $[15,16]$. Fly ash is similar to cement in composition $[17,18]$, and the incorporation of fly ash also changes the strength properties of the soil [19-23]; however, the content of fly ash is too high and will pollute the environment, which limits the popularization and application of fly ash.

However, existing studies only focus on enhancing the strength of soil by mixing fly ash but seldom center on the other performance and widespread application of ash-mixed soil. Especially, there is a lack of research on application of ecological substrate made of ash-mixed soil to ecological restoration. This paper proposes the use of fly ash produced from waste incineration to prepare ecological slope protection substrate, which not only enhances soil strength and promotes plant growth but also saves land resources and protects the environment. It is an innovative idea to study its feasibility as the substrates of ecological slope protection and to realize the resource utilization of waste fly ash. A series of tests were performed to investigate the following questions. (1) The influence of fly ash content on the shear strength of substrates with different moisture contents. (2) The effect of ash content on the plant growth performance of the substrate and the effect of different root contents on the shear strength of the substrate. (3) The influence of the amount of fly ash on the concentration of contaminated ions and the surrounding ecological environment.

\section{Materials and Methods}

2.1. Materials. The test soil was the clay obtained from the construction site of Hubei University of Technology. According to the method of the Geotechnical Test Regulations SL237-1999, the plasticity index of clay was measured by the liquid limit and plastic limit methods. The relative density of clay was measured by the pycnometer method, and the optimum moisture content and maximum dry density were obtained by compaction test. The basic properties of the test clay are listed in Table 1 .

Fly ash was obtained from the Chang Shankou waste incineration thermal power plant in Wuhan. An X-ray fluorescence spectrometer (XRF) was used to detect the main fly ash components, which mainly existed as oxides; most of the content was $\mathrm{SiO}_{2}$ and $\mathrm{CaO}$. The main fly ash contents are summarized in Table 2. After the digestion of the fly ash sample, the heavy metal content was measured by plasma emission spectroscopy, and the test results are listed in Table 3.

Cynodon dactylon (Cynodon dactylon (L.) Pers) was selected as the slope protection plant. The distribution density and growth period of plants have significant influence on the slope protection. Cynodon dactylon is a perennial herb with rhizomatous and creeping branches, and the roots are fine and tough and is an excellent slope protection plant. It has the characteristics of strong survivability, well-developed root system, and strong tensile resistance and soil retention. The research selects Cynodon
TABLe 1: Basic properties of test clay.

\begin{tabular}{lccccc}
\hline $\begin{array}{l}\text { Liquid } \\
\text { limit } \\
(\%)\end{array}$ & $\begin{array}{c}\text { Plastic } \\
\text { limit } \\
(\%)\end{array}$ & $\begin{array}{c}\text { Plasticity } \\
\text { index }\end{array}$ & $\begin{array}{c}\text { Relative } \\
\text { density }\end{array}$ & $\begin{array}{c}\text { Optimum } \\
\text { moisture } \\
\text { content }(\%)\end{array}$ & $\begin{array}{c}\text { Maximum } \\
\text { dry density } \\
\left(\mathrm{g} \cdot \mathrm{cm}^{-3}\right)\end{array}$ \\
\hline 43.8 & 21.7 & 22.1 & 2.78 & 24.9 & 1.61 \\
\hline
\end{tabular}

TABLE 2: Main composition of fly ash (\%).

\begin{tabular}{ccccccccc}
\hline $\mathrm{SiO}_{2}$ & $\mathrm{CaO}$ & $\mathrm{Al}_{2} \mathrm{O}_{3}$ & $\mathrm{Fe}_{2} \mathrm{O}_{3}$ & $\mathrm{~K}_{2} \mathrm{O}$ & $\mathrm{MgO}$ & $\mathrm{Na}_{2} \mathrm{O}$ & $\mathrm{P}_{2} \mathrm{O}_{5}$ & Others \\
\hline 29.35 & 21.78 & 9.57 & 5.23 & 3.42 & 3.63 & 3.21 & 1.23 & 22.58 \\
\hline
\end{tabular}

TABLe 3: Heavy metal content in fly ash (mg/kg).

\begin{tabular}{lccccc}
\hline $\mathrm{Pb}$ & $\mathrm{Cd}$ & $\mathrm{Cu}$ & $\mathrm{Zn}$ & $\mathrm{Hg}$ & $\mathrm{Ni}$ \\
\hline 1517.3 & 38.2 & 572.1 & 3264.9 & 4.5 & 72.3 \\
\hline
\end{tabular}

dactylon as the research object as it is widely distributed in most parts of the world, which is a high-quality slope protection plant commonly used on ecological slopes, but also the natural fibrous roots of the soil seed bank. It is very representative $[24,25]$.

\subsection{Shear Test of Substrate Not Planted with Cynodon dactylon Plants (Test 1)}

2.2.1. Test Scheme. In test 1 , the influence of the plant root system was not considered. By controlling the moisture and fly ash contents, the influence of these two factors on the shear strength of soil was analyzed. Five moisture contents and five ash contents were adopted to form 25 groups of samples for full probability tests. Four samples were prepared for each group, and direct shear tests were conducted under four vertical pressures $(50 \mathrm{kPa}, 100 \mathrm{kPa}$, $200 \mathrm{kPa}$, and $400 \mathrm{kPa}$ ). The shear strength and cohesion of the soil first decreased with the moisture content and reached their maxima as they approached the optimum moisture content $[26,27]$. Therefore, the moisture content of the five samples is near the optimum moisture content of the plain soil (soil without fly ash) of $24.9 \%$, which is respectively $16.9 \%, 20.9 \%, 24.9 \%, 28.9 \%$, and $32.9 \%$. Heavy metals in the fly ash retard plant growth [28]; hence, the amount of fly ash in the soil should not be overly large. Accordingly, in this test, the fly ash content (the mass ratio of fly ash to soil) was limited to a maximum of $20 \%$; the fly ash contents of the five samples were $0 \%$, $5 \%, 6.7 \%, 10 \%$, and $20 \%$. The test scheme for the sample with a $16.9 \%$ moisture content is listed in Table 4; the schemes for the samples with the remaining moisture content were similar.

2.2.2. Sample Preparation. First, the test soil and fly ash were air-dried, crushed, and sifted through a $2 \mathrm{~mm}$ sieve. The clay was mixed with waste incineration fly ash to form fly ash substrate. Thereafter, an electronic scale with an accuracy of $0.001 \mathrm{~g}$ was employed to weigh the plain soil and the corresponding fly ash according to the fly ash content. The plain 
TABLE 4: Test scheme (16.9\% moisture content).

\begin{tabular}{lccc}
\hline Number & $\begin{array}{c}\text { Moisture content } \\
(\%)\end{array}$ & $\begin{array}{c}\text { Ash content } \\
(\%)\end{array}$ & $\begin{array}{c}\text { Vertical pressure } \\
(\mathrm{kPa})\end{array}$ \\
\hline 1 & & 0 & $50,100,200,400$ \\
2 & & 5 & $50,100,200,400$ \\
3 & 16.9 & 6.7 & $50,100,200,400$ \\
4 & & 10 & $50,100,200,400$ \\
5 & & 20 & $50,100,200,400$ \\
\hline
\end{tabular}

soil and fly ash were then mixed evenly in a box. The required water volume was measured according to the predetermined moisture content. The ash and soil mixture was gradually sprayed with water while it was stirred to achieve an even mix. Thereafter, the soil samples were placed into a ring knife with an inner diameter and height of 6.18 and $2 \mathrm{~cm}$, respectively. The samples prepared for test 1 are shown in Figure 1(a).

2.2.3. Shear Strength Test of Soil Samples. Quick shear tests were performed with the ZJ manual portable straincontrolled direct shear apparatus. The hand wheel was rotated at a uniform speed of $6 \mathrm{rpm}$; the samples were sheared in 3-5 min. The shear strengths of soil samples under four vertical pressures were tested. According to the test data, the fitting curve was drawn with the vertical pressure as abscissa and the shear strength of ash-mixed soil as ordinate. According to Coulomb's formula, $\tau_{f}=c+\sigma \tan \varphi$, the cohesion $c$ and internal friction angle of the ash-mixed soil under different conditions were calculated based on the fitting line.

\subsection{Shear Test of Fly Ash Substrate Planted with Cynodon dactylon (Test 2)}

2.3.1. Test Scheme. Test 2 considered the effects of the roots of Cynodon dactylon which was plated in the test soil. The moisture content was measured on site, and the effects of fly ash content and root system on the shear strength of substrate were considered. The fly ash content was consistent with test 1 . The side slope protection plant Cynodon dactylon was sown on the slope at $20 \mathrm{~g} / \mathrm{m}^{2}$ [29]. When Cynodon dactylon had thrived and the root system had spread deeper into the soil, the root-soil composite shear strength test was implemented.

2.3.2. Sample Preparation. Firstly, a $90 \mathrm{~cm}$ long, $60 \mathrm{~cm}$ wide, and $10 \mathrm{~cm}$ high uncovered rectangular test block was fabricated. In the middle, six small square test blocks, $30 \mathrm{~cm}$ long, $30 \mathrm{~cm}$ wide, and $10 \mathrm{~cm}$ high, were separated by thin plates. Cynodon dactylon was planted in the test block. Using the same method in test 1 , the test soil was crushed and sifted and then mixed with $0 \%, 5 \%, 6.7 \%, 10 \%$, and $20 \%$ of the preset fly ash content in the box. After weighing the seeds of Cynodon dactylon of $20 \mathrm{~g} / \mathrm{m} 2$, the seeds are to be mixed with the fine soil prepared beforehand; the seeds were then evenly sown in each test block. Finally, a thin layer of soil, approximately $1 \mathrm{~mm}$ thick, was spread to cover the seeds. A nonwoven cloth was laid on it, and thereafter the seeds were watered. The germinated specimens of Cynodon dactylon for test 2 are shown in Figure 1(b).

2.3.3. Direct Shear Test. After half a year since planting in plain soil, the roots of Cynodon dactylon grew to approximately $25 \mathrm{~cm}$, and the root system of mature Cynodon dactylon is shown in Figure 1(c). After the growth heights of Cynodon dactylon in different samples were measured (using a ruler), the upper stems and leaves of the plant were removed with a pair of scissors and thereafter leveled. From each block with the same fly ash content, four soil samples were collected using a ring knife and the samples were numbered.

Thereafter, two small samples were obtained from the upper and middle layers of the remaining soil of the test block. The soil moisture content was measured according to the drying method prescribed in the code for Geotechnical Experiments (SL237-1999). The average value of the moisture content of the four soil samples was considered as the moisture content of the test block.

The shear strength of soil samples was tested by the ZJ manual portable strain gauge-controlled direct shear apparatus. The test procedure was the same as that in test 1 .

2.3.4. Root Condition. After the direct shear test, the soil samples were taken from the shear box and the roots were separated from the soil. The roots were washed with water. After washing, the roots of the Cynodon dactylon are as shown in Figure 2(a), which were then baked at $85^{\circ} \mathrm{C}$ until the weight was constant and the weight was taken out, and the roots of the Cynodon dactylon were dried, as shown in Figure 2(b). The root dry mass $m_{\mathrm{s}}$ corresponding to each sample was measured to obtain an average value under the same ash content, that is, $m_{\mathrm{r}}=m s / v$ is the root content at different ash content. In the formulation, $m_{\mathrm{r}}$ is the root content $\left(\mathrm{g} / 60 \mathrm{~cm}^{3}\right), m_{\mathrm{s}}$ is the root dry mass (g), $v$ is the soil sample volume, and the annular knife volume is $60 \mathrm{~cm}^{3}$.

\subsection{Heavy Metal Precipitation Test of Fly Ash Substrate Planted with Cynodon dactylon (Test 3)}

2.4.1. Sample Preparation. According to the method employed in experiment 2 , six square test blocks, each with a $30 \mathrm{~cm}$ length, $30 \mathrm{~cm}$ width, and $10 \mathrm{~cm}$ height, were fabricated. Two $2 \mathrm{~cm}$ diameter holes were made in each small wooden lattice, and a large-diameter plastic bowl was placed under the holes for the collection of leachate. The edge joints were sealed with impermeable film barriers, and the wooden lattices have high and low supports, which are shown in Figure 2(c). Cynodon dactylon plants were planted in soil with $0 \%, 5 \%, 6.7 \%, 10 \%$, and $20 \%$ fly ash content according to the same method employed in test 2 .

2.4.2. Leachate Collection. First, the filter paper was folded to form a funnel, and a 2-mm filter outlet was torn at the 


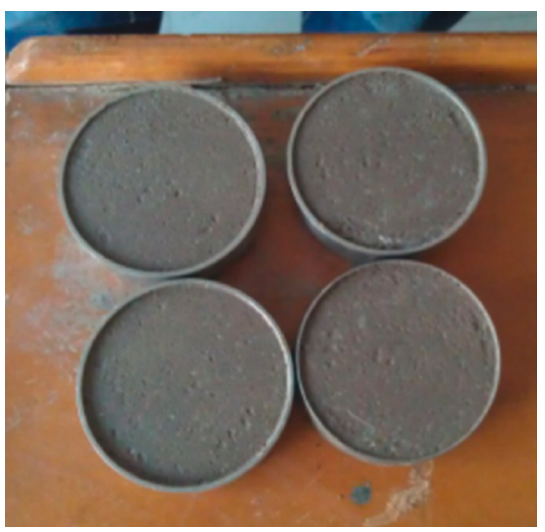

(a)

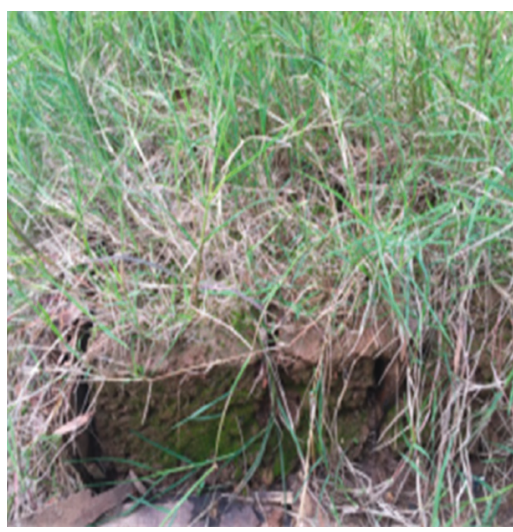

(b)

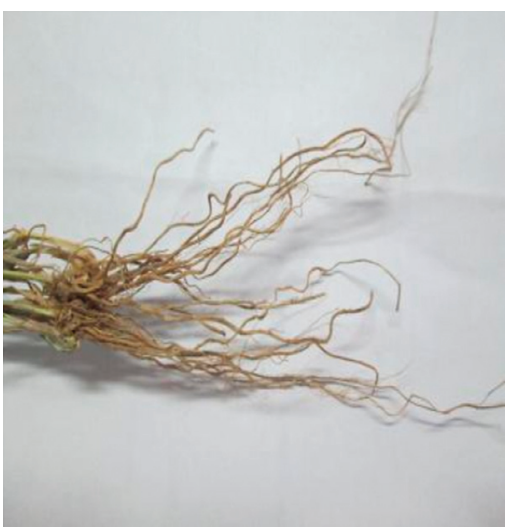

(c)

Figure 1: Preparation for the three tests. (a) Picture of samples prepared in test 1. (b) Sample diagram of Cynodon dactylon after germination in test 2. (c) Root system of the mature Cynodon dactylon.

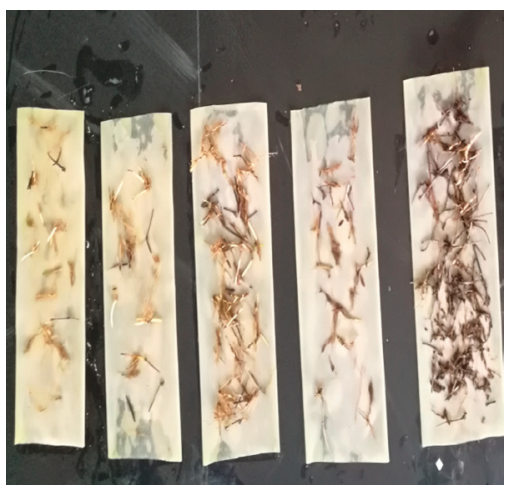

(a)

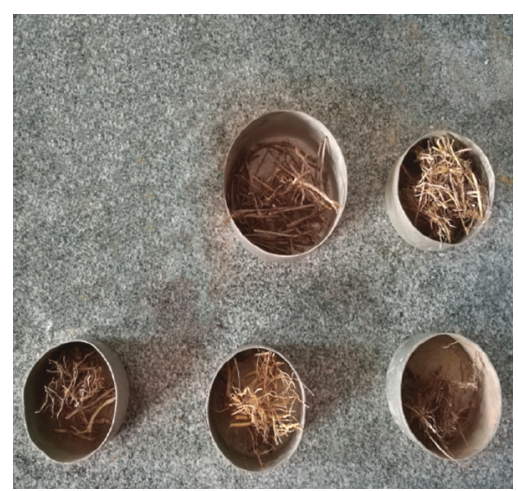

(b)

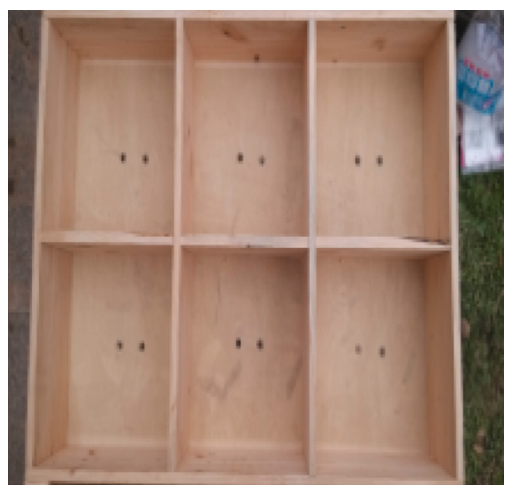

(c)

Figure 2: Preparation for the three tests. (a) Root of Cynodon dactylon after cleaning. (b) Root of Cynodon dactylon after drying. (c) Diagram of the test block.

bottom of the paper. Thereafter, the collected leachate was transferred from the plastic bowl into a plastic bottle using the funnel. Each plastic bottle was labeled according to the time of collection and the amount of fly ash. The bottled leachate was then brought to the laboratory for ion concentration analysis.

2.4.3. Ion Detection. The concentration of chloride ion was determined by silver nitrate titration [30], whereas the concentration of heavy metal elements was obtained by atomic absorption spectrophotometry. Because the concentration of certain heavy metal ions was extremely low (to the extent that it was below the limit of surface water environmental quality standard), only those with higher $\mathrm{Cl}$, $\mathrm{Cu}$, and $\mathrm{Zn}$ concentrations in the leaching solution are listed here for analysis.

\section{Results and Analysis}

3.1. Effects of Ash Content and Moisture Content. The relationship between shear strength and the amount of fly ash added at different moisture contents in test 1 is shown in
Figure 3; when the moisture content is $16.9 \%$, the fitting curve of shear strength and direct stress is shown in Figure 4; the relationship between the shear strength index and the amount of fly ash added is shown in Figure 5.

It can be observed in Figure 3 that under certain vertical pressures and moisture contents, the shear strength of the substrate first increased and thereafter decreased with the increase in the amount of added ash. Nevertheless, compared with plain soil ( $0 \%$ ash content), there was a certain degree of improvement. But the content of fly ash is not directly proportional to the shear strength. There was an optimum ash content that maximized the shear strength. Under different vertical pressures, the optimum amount of ash differed. When the vertical pressures were $50 \mathrm{kPa}$ and $100 \mathrm{kPa}$, the optimum ash content was $5 \%$. In this case, the maximum shear strengths were 1.58 and 1.67 times that of plain soil, respectively. When the vertical pressure was $200 \mathrm{kPa}$, the optimum ash content was $6.7 \%$, and the maximum shear strength was 1.52 times that of plain soil. When the vertical pressure was $400 \mathrm{kPa}$, the optimum ash content was $20 \%$, and the shear strength was at most 1.59 times that of plain soil. It can be known that when the moisture content is constant and in the range of $16.9 \%-$ 


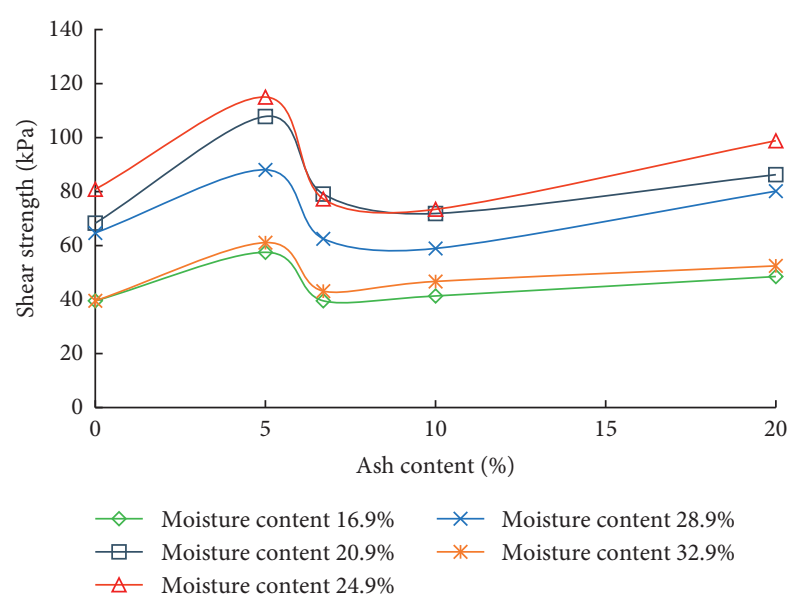

(a)

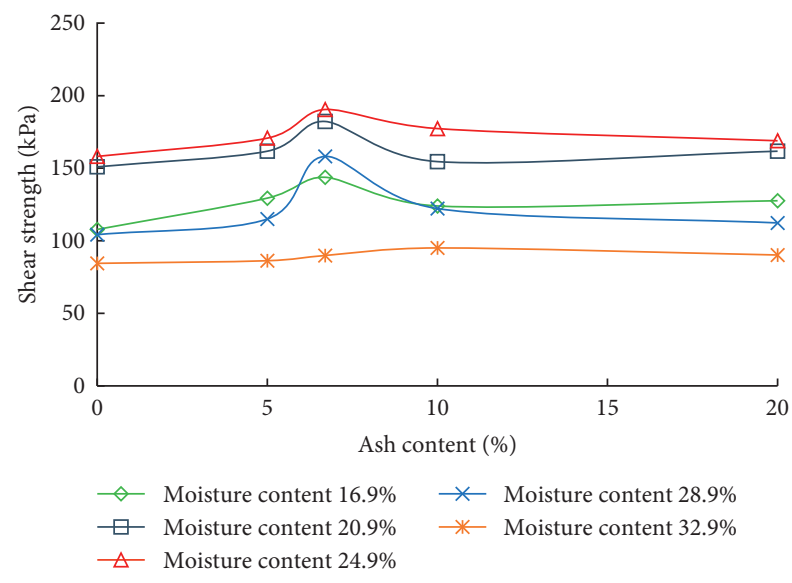

(c)

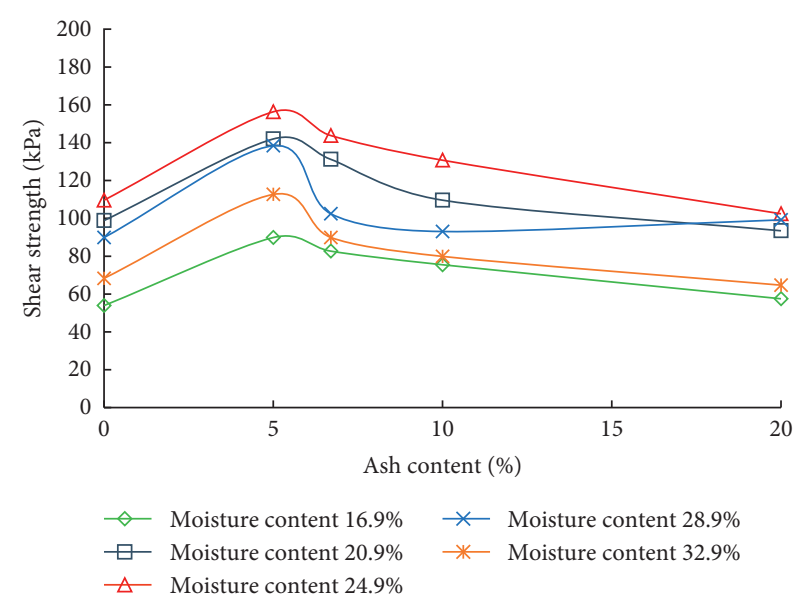

(b)

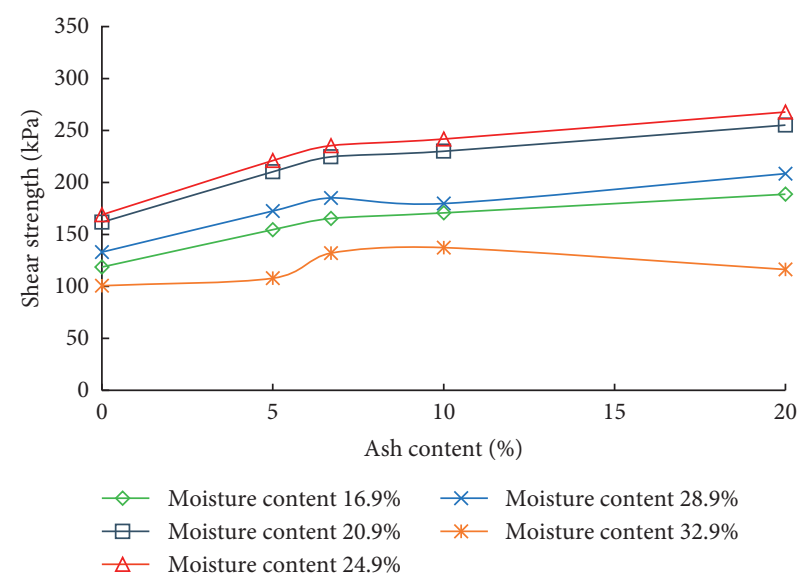

(d)

FIgURE 3: Curve of shear strength vs. fly ash ratio under (a) $50 \mathrm{kPa}$, (b) $100 \mathrm{kPa}$, (c) $200 \mathrm{kPa}$, and (d) $400 \mathrm{kPa}$.

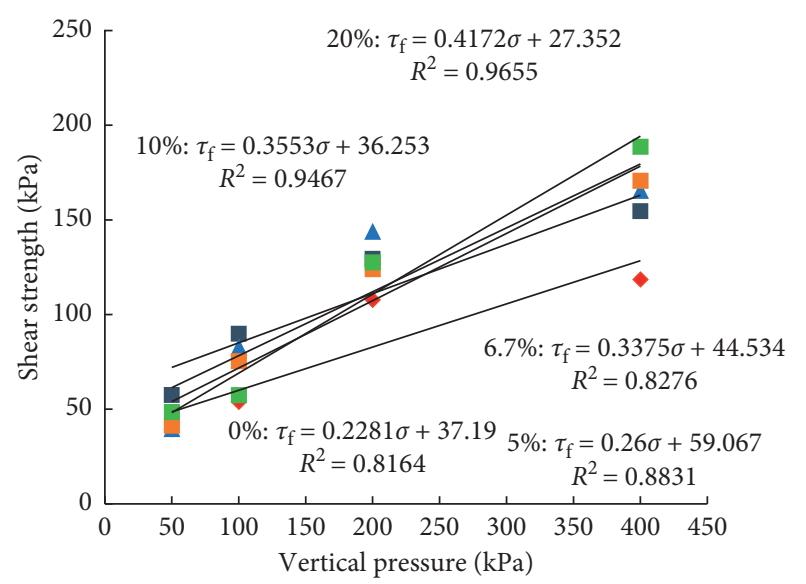

FIGURE 4: Fitting curve of shear strength and direct stress. The moisture content is $16.9 \%$.

$32.9 \%$, the optimum ash content increases with the increase of vertical pressure. When the moisture content is $16.9 \%$, the fitting curve of shear strength and direct stress is shown in Figure 4 and other moisture content is similar to the rule. Shear strength is related not only to internal characteristic cohesion and internal friction angle of ash-mixed soil but also to external normal stress. It can be seen that with the increase of ash content, cohesion increases first and then decreases, reaching the maximum when the ash content is $5 \%$, while the internal friction angle increases all the time. The variation mechanism of cohesion and internal friction angle with ash content is explained in Figure 5. That is, the intercept between the shear stress-direct stress curve and the $y$-axis increases first and then decreases, while the slope of the relationship line increases continuously. When the direct stress was smaller $(50 \mathrm{kPa}$ and $100 \mathrm{kPa})$, the cohesive force of $5 \%$ ash content is the maximum. With the increase of ash content, the slope of the relationship line increases insufficiently to exceed the influence of cohesive force. However, with the increase of ash content, the slope of the curve increases and the intersection of the relationship line appears. When the vertical pressure was $200 \mathrm{kPa}$, the aggregate of cohesive force and friction resistance is the maximum when the ash content is $6.7 \%$. Therefore, under a certain moisture content and vertical pressure, blindly increasing the fly ash incorporation ratio does not necessarily improve the shear strength of substrate; in contrast, it may even reduce it.

Under the condition of a certain ash content and vertical pressure, the shear strength of the substrate 
increased first and thereafter decreased with the increase of moisture content. The shear strength was highest at the optimum moisture content of $24.9 \%$. Under different vertical pressures, the influence of moisture content on shear strength slightly varied. When the vertical pressure was $50 \mathrm{kPa}$ and $100 \mathrm{kPa}$, the order of shear strength values at different moisture contents was $24.9 \%>20.9 \%>28.9 \%$, and shear strengths corresponding to moisture contents of $16.9 \%$ and $32.9 \%$ were the lowest. When the vertical pressure was $200 \mathrm{kPa}$ and $400 \mathrm{kPa}$, the order of shear strength values at different moisture contents was $24.9 \%$ $>20.9 \%>28.9 \% \quad(16.9 \%)>32.9 \%$. The influence of moisture content on the shear strength of ash-mixed soil is mainly manifested in two aspects. On the one hand, moisture content affects the shear strength of soil by changing its matric suction and with the increase of moisture content, the shear strength of unsaturated soil decreases [31]. On the other hand, water reacts with silica, calcium, aluminum, iron, and other active materials in fly ash producing a concrete reaction, which increases the cohesive force of ash-mixed soil and improves its shear strength. When the moisture content of ash-mixed soil is smaller $(\leq 24.9 \%)$, the concrete reaction takes the main advantage and increases the shear strength of ash-mixed soil. When the moisture content of ash-mixed soil is larger $(\geq 24.9 \%)$, there is not enough water for concrete reaction, the influence of matrix suction is the main advantage, and the shear strength of ash-mixed soil decreases.

It can be observed in Figure 5(a) that as the ash content increased, the cohesive force in the ash-mixed soil first increased and thereafter decreased. When the moisture content was $28.9 \%$, the ash content was $6.7 \%$. In this case, the cohesive force in the ash-mixed soil was the maximum. The ash content corresponding to the maximum cohesive force in the remaining moisture content was $5 \%$. It can be seen that the ash content that was favorable to soil cohesion was between $5 \%$ and $6.7 \%$. Silicon, calcium, aluminum, iron, and other active substances in fly ash will have a concrete reaction with water. With the increase in ash content, the concrete reaction increased and the cohesion of the substrate increased. However, when the amount of ash added exceeded $5 \%-$ $6.7 \%$, the excess fly ash had no water to combine with; consequently, the concrete reaction was halted, and the cohesive force was decreased.

It can be noted in Figure 5(b) that the internal friction angle of the substrate increased as the ash content increased. Because after concrete reaction between fly ash and water, some granules larger than the clay particles were produced, resulting in increased friction force and internal friction angle. When the ash content was between $0 \%$ and $5 \%$, the amount of fly ash was extremely small, and the internal friction angle of the substrate gradually increased. When the ash content was between $5 \%$ and $6.7 \%$, the hardcondensing reaction was sufficient, and the internal friction angle of the substrate increased. When the ash content was between $6.7 \%$ and $20 \%$, the concrete reaction was halted. However, the fly ash particles remained larger than the clay particles; thus, the internal friction angle also increased but is unobvious. Therefore, adding fly ash to soil was beneficial to increase its shear strength and internal friction angle.

\subsection{Effects of Plant Root System}

3.2.1. Plant Growth Status and Root System Testing. The growth heights of the Cynodon dactylon in different fly ash substrate soils were measured (using a ruler). In each sample with ash content, 5 representative plants were selected and their heights were measured, and the average value is listed in Table 5. The root contents in the soil samples of the ashmixed soil measured after the direct shear test are also listed in Table 5 .

It can be observed from the list in Table 5 that as the amount of fly ash added increased, the height and root content of the Cynodon dactylon first increased and thereafter decreased; their values reached the maximum when the fly ash content was $5 \%$. However, when the fly ash content was less than $20 \%$, the growth state of Cynodon dactylon grown in soil with fly ash was better than that of the same plant grown in soil without fly ash. The nutrients from the ash-mixed soil caused the plant's height to increase and its roots to grow rapidly. When the fly ash content exceeded 5\%, the amount of calcium, phosphorus, and potassium benefited the plants grown in soil with fly ash, whereas the heavy metal elements present in the ash inhibited the height and reduced the root content. Nevertheless, overall, their growth was better than that of Cynodon dactylon grown in plain soil. Therefore, nutrients in the substrate can promote the growth of plants, which is also consistent with the research of Ray Sarkar et al. [11].

3.2.2. Impact on Shear Strength Indicators. The moisture contents of soil samples (measured on-site) with varied fly ash content in test 2 are summarized in Table 6 . The table shows that the moisture content of soil samples was between $16.7 \%$ and $18.9 \%$. The results of test 2 were compared with that of the soil sample with a moisture content of $16.9 \%$ (sample 1). The change rule in the shear strength index of the soil sample with varied fly ash contents in the presence or absence of Cynodon dactylon is shown in Figure 6.

Figure 6 shows that the cohesive force and internal friction angle have the same tendency as the change in fly ash content (with the presence or absence of Cynodon dactylon). As the amount of fly ash increased, the cohesive force first increased and thereafter decreased; the maximum was attained when the fly ash content was $5 \%$. The internal friction angle increased as the amount of fly ash increased.

It has been noted that the cohesive force of soil planted with Cynodon dactylon increased. This improvement was the result of the reinforcing and biological effects of the plant roots; the cohesive force of the root-soil composite was higher than that of plain soil. When the amount of fly ash ranged from $0 \%$ to $5 \%$, the increase in cohesive force 


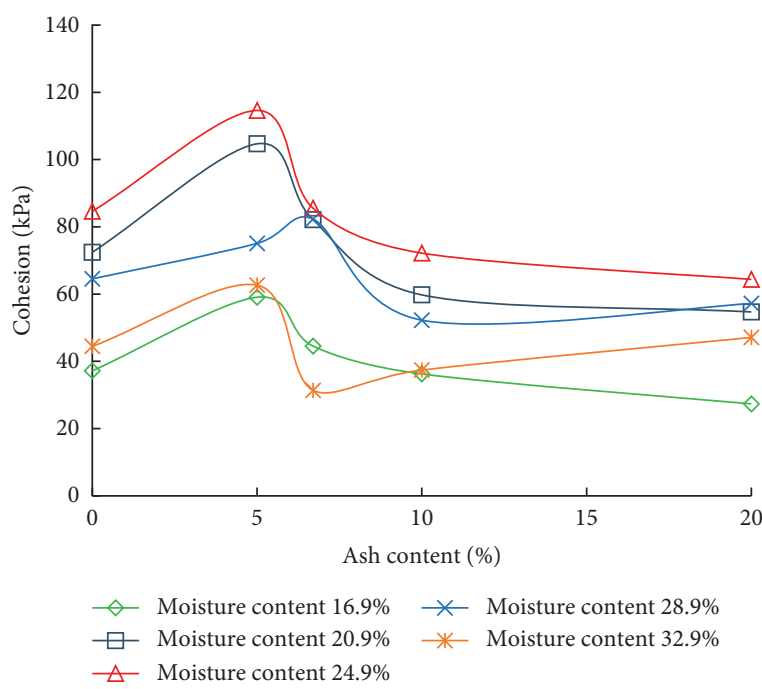

(a)

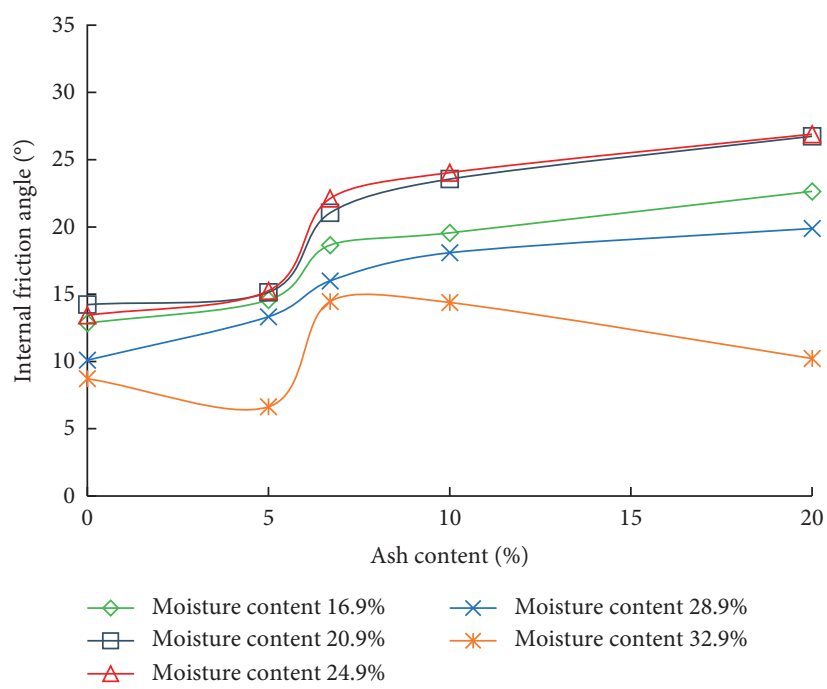

(b)

Figure 5: Curve of shear strength index vs. ratio of fly ash: (a) cohesion; (b) internal friction angle.

TABLE 5: Growth heights of Bermuda grass and root contents in soil samples with different fly ash ratios.

\begin{tabular}{lcc}
\hline $\begin{array}{l}\text { Ash content } \\
(\%)\end{array}$ & $\begin{array}{r}\text { Cynodon dactylon height } \\
(\mathrm{mm})\end{array}$ & $\begin{array}{r}\text { Root content } \\
\left(\mathrm{g} / 60 \mathrm{~cm}^{3}\right)\end{array}$ \\
\hline 0 & 250 & 0.2 \\
5 & 316 & 0.5 \\
6.7 & 314 & 0.4 \\
10 & 308 & 0.3 \\
20 & 267 & 0.25 \\
\hline
\end{tabular}

TABLE 6: Moisture content of soil samples with different fly ash ratios.

\begin{tabular}{lc}
\hline Ash content $(\%)$ & Moisture content $(\%)$ \\
\hline 0 & 18.9 \\
5 & 18.3 \\
6.7 & 17.6 \\
10 & 16.8 \\
20 & 16.7 \\
\hline
\end{tabular}

was most distinct-from $47 \%$ to $52 \%$; when the fly ash content ranged from $5 \%$ to $10 \%$, the increase in cohesive force was also evident-from $30 \%$ to $47 \%$; when the amount of fly ash was from $10 \%$ to $20 \%$, the increase in cohesion was at its lowest-from $15 \%$ to $30 \%$. Taking the fly ash content as abscissa and the cohesive force and root content $\left(m_{\mathrm{r}}\right)$ as ordinates, the influence $(\Delta C)$ of the root system is shown in Figure 7. It can be seen that $\Delta C$ first increased and thereafter decreased with the increase in fly ash content in soil planted with Cynodon dactylon. The curve trend was similar to the growth trend of the plants. When the fly ash content was 5\%, the root content of Cynodon dactylon was at its highest, and the reinforcing and biological effects of the root system were the optimum. At this moment, the increment in soil cohesion was at its maximum. When the ash content was more than $5 \%$, the root growth was inhibited, and the reinforcing effect of roots was weakened. Evidently, cohesion was affected by the ash content and root system.

The internal friction angle of soil planted with Cynodon dactylon also slightly increased; the rate of increase gradually decreased from $6.4 \%$ to $0.9 \%$. The effect $(\Delta \varphi)$ of the root system when the internal friction angle and root content $\left(m_{\mathrm{r}}\right)$ was the ordinates and fly ash content was the abscissa is shown in Figure 6. It can be observed that $\Delta \varphi$ had no correlation with the root content. With the increase in the root content, the decrease in the soil void ratio and the increase in the internal friction angle were uncertain. The amount of fly ash had a leading influence on the internal friction angle. Plant roots primarily increased the cohesion of soil, but their influence on the internal friction angle was negligible (an observation consistent with the study of Zong et al.) [32].

3.3. Environmental Impact of Exudates. In test 3, the amount of fly ash added was the abscissa, and the ion concentration was the ordinate. The concentration of the leachate collected at different times with the fly ash content is shown in Figure 8 .

Figure 8 shows that the concentration of $\mathrm{Cl}, \mathrm{Cu}$, and $\mathrm{Zn}$ ions increased with the amount of fly ash but decreased as time goes by (the concentration of $\mathrm{Cl}$ and $\mathrm{Zn}$ ions is similar to that of $\mathrm{Cu}$ ions). Therefore, the earliest collected leachate of the $20 \%$ ash-mixed soil can probably pollute the environment. The concentrations of the three leachates and their standard limits on surface water environment according to the V-type water quality of Standard Limit Value of Basic Items of Surface Water Environmental Quality Standard (GB3838-2002) are listed in Table 7. The list indicates that the concentration of each ion in the leachate was below the standard limit. Hence, the concentrations of these elements conformed to the national standard; accordingly, the 


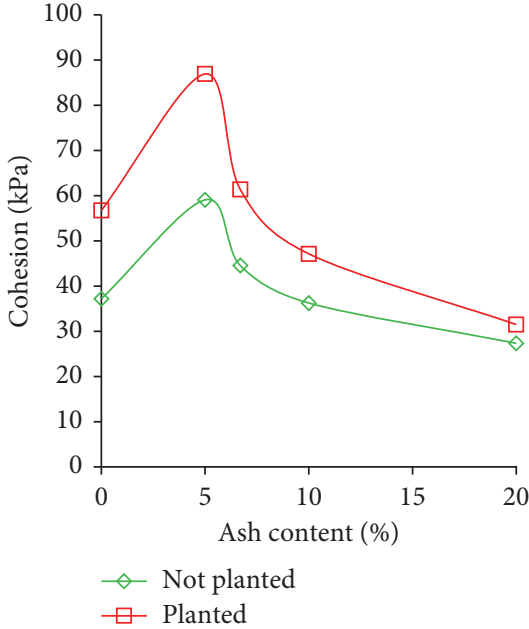

(a)

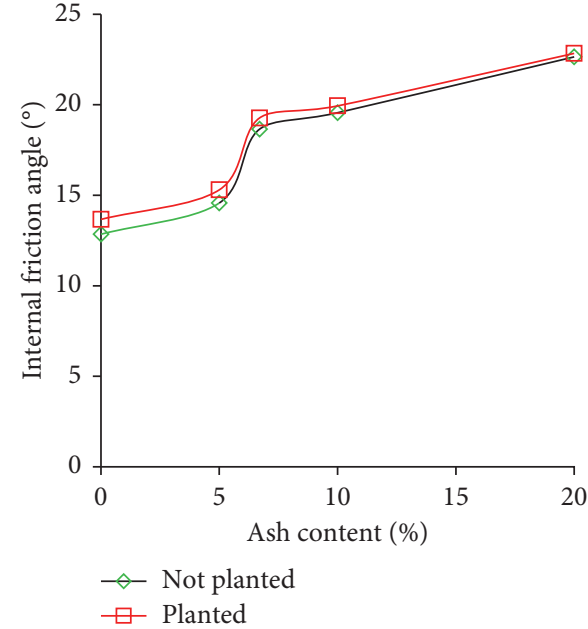

(b)

FIgURE 6: Curve of shear strength index vs. fly ash content under two conditions: (a) cohesion; (b) internal friction angle.

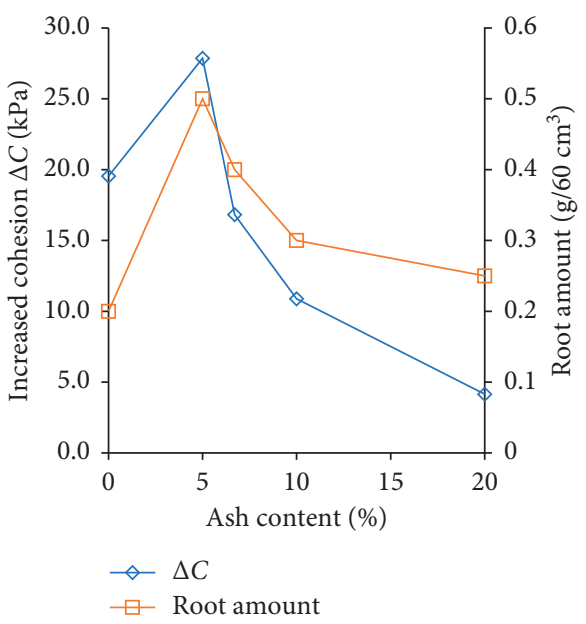

(a)

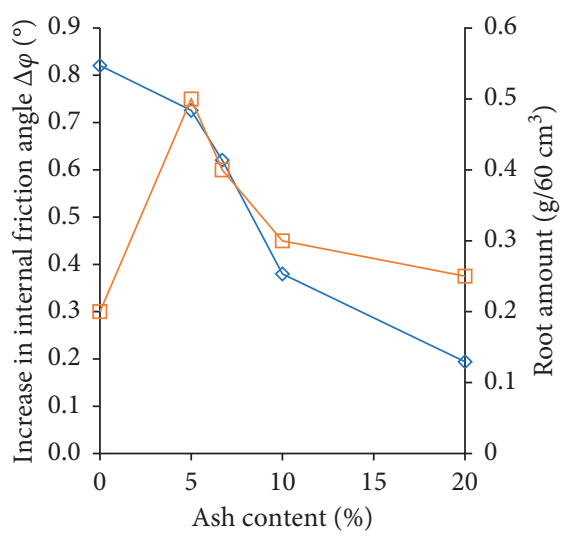

$\neg \Delta \varphi$

$\square$ Root amount

FiguRE 7: Influence curve of roots on soil shear strength index and root content: (a) cohesion; (b) internal friction angle.

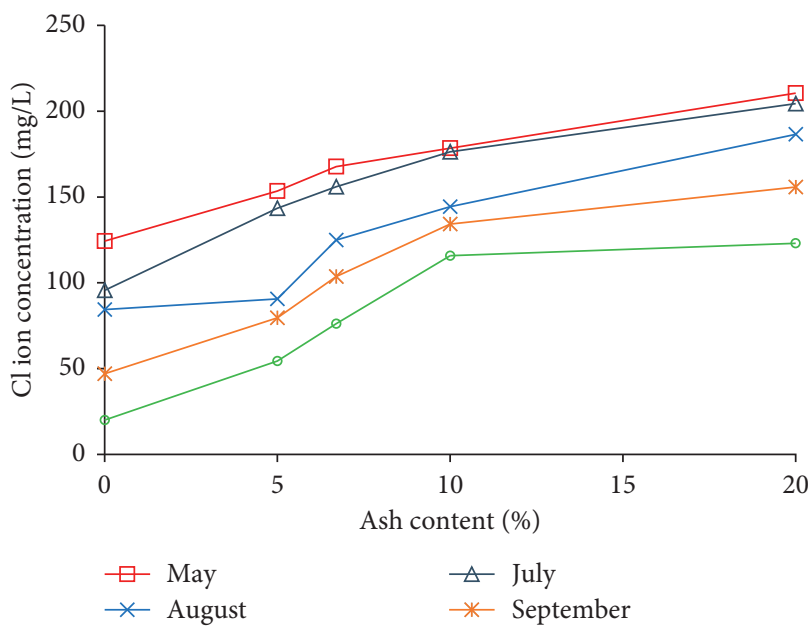

(a)

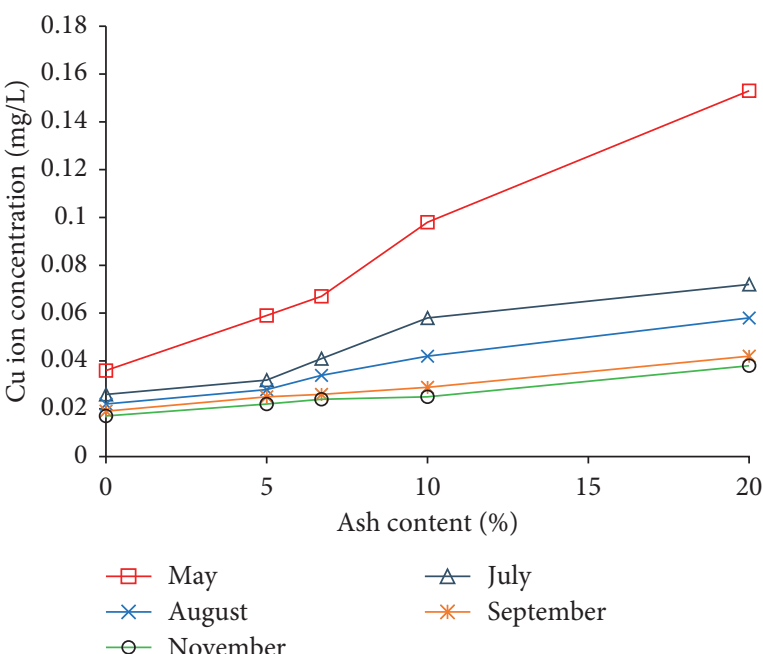

(b)

Figure 8: Continued. 


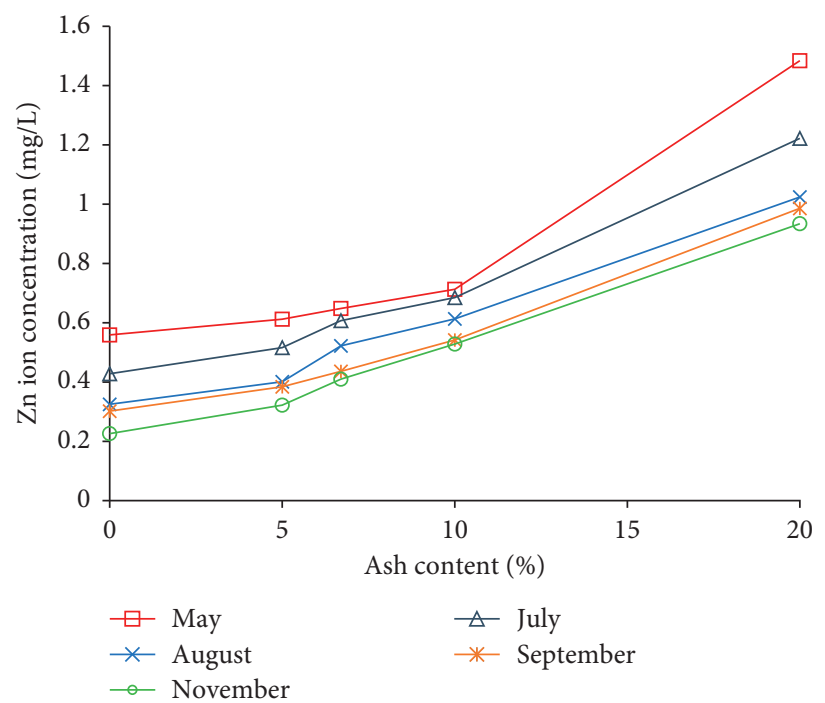

(c)

Figure 8: Curve of ion concentration vs. fly ash ratio: (a) $\mathrm{Cl}$ ion concentration; (b) $\mathrm{Cu}$ ion concentration; (c) $\mathrm{Zn}$ ion concentration.

TABLE 7: Leachate ion concentrations and their limits at 20\% fly ash ratio.

\begin{tabular}{lcc}
\hline Ion species & $\begin{array}{c}\text { Leachate ion concentration } \\
(\mathrm{mg} / \mathrm{L})\end{array}$ & $\begin{array}{c}\text { Concentration limit } \\
(\mathrm{mg} / \mathrm{L})\end{array}$ \\
\hline $\mathrm{Cl}$ & 220.7 & 250 \\
$\mathrm{Cu}$ & 0.153 & 1.0 \\
$\mathrm{Zn}$ & 1.526 & 2.0 \\
\hline
\end{tabular}

leachate will not cause environmental pollution and can meet the ecological requirements.

\section{Conclusions}

(1) Fly ash can improve the shear strength of soil to a certain extent; at most, up to 1.67 times that of plain soil; therefore, the strength of the substrate meets the requirements.

(2) The shear strength of the substrate first increased and thereafter decreased with the increase of the moisture content. The substrate's shear strength attained the maximum at the optimum moisture content of $24.9 \%$.

(3) With the increase of ash content, the cohesion of substrate first increased and thereafter decreased. The amount of fly ash in the substrate beneficial to soil cohesion was found to be $5 \%-6.7 \%$. The internal friction angle of the substrate increased with the amount of fly ash. When this amount was $5 \%-6.7 \%$, the internal friction angle of soil rapidly increased.

(4) The cohesion and internal friction angle of substrate planted with Cynodon dactylon increased. The cohesion of the substrate was positively correlated with the plant's root content, whereas the internal friction angle was only slightly influenced by this content.
Hence, the root system of plants mainly improves the cohesive force of the substrate.

(5) The height of the Cynodon dactylon in the substrate is higher than the height of the plants that grow in the plain soil; nutrients in the substrate are conducive to plant growth. In the eco-slope protection soil with a fly ash content of less than $20 \%$, the concentration of polluted ions was below the V-type water quality standard limit; hence, the substrate will not pollute the environment and can meet the ecological requirements.

\section{Data Availability}

The data used to support the findings of this study are available from the corresponding author upon request.

\section{Conflicts of Interest}

The authors declare that there are no conflicts of interest regarding the publication of this article.

\section{Authors' Contributions}

J. W. provided the idea; J. Z. wrote the manuscript and revised the paper; H. L. X. conducted the experiment; and Q. M. revised the manuscript.

\section{Acknowledgments}

This research was funded by the National Key R\&D Program of China (No. 2016YFC0502208), and National Natural Science Foundation of China (No. 51608182, 51678223).

\section{Supplementary Materials}

The first part of the data is measured by direct shear test, and the shear strength varies with the ash content under different 
water content conditions, as shown in Figure 2 of the manuscript; the data in the second part is the change of the shear strength index with the ash content, as shown in Figure 3 of the manuscript; the data in the third part is the relationship between the shear strength index of different conditions (planting Cynodon dactylon and unplanted Cynodon dactylon) and the effect of the root system on soil shear strength index and root content, such as in manuscript Figures 4 and 5; the data in the fourth part is the variation of the ion concentration collected at different times with the ash content, as shown in Figure 6 of the manuscript. (Supplementary Materials)

\section{References}

[1] J.-S. Han and C.-G. Kim, "Characterization of molecular biological indicators to define stabilization of landfills," Korean Journal of Chemical Engineering, vol. 27, no. 3, pp. 868-873, 2010.

[2] X. Liu, X. Zhao, H. Yin, J. Chen, and N. Zhang, "Intermediatecalcium based cementitious materials prepared by MSWI fly ash and other solid wastes: hydration characteristics and heavy metals solidification behavior," Journal of Hazardous Materials, vol. 349, pp. 262-271, 2018.

[3] R. Valencia, W. van der Zon, H. Woelders, H. J. Lubberding, and H. J. Gijzen, "The effect of hydraulic conditions on waste stabilisation in bioreactor landfill simulators," Bioresource Technology, vol. 100, no. 5, pp. 1754-1761, 2009.

[4] S. Yang, L. Lin, S. P. Li et al., "Assessment and comparison of three high-aluminum fly ash utilization scenarios in Inner Mongolia, China using an eco-efficiency indicator," Waste Management \& Research the Journal of the International Solid Wastes \& Public Cleansing Association Iswa, vol. 35, no. 5, pp. 515-524, 2017.

[5] J. H. Hu, H. Wang, H. L. Liu et al., "Gasification-melting technology of municipal solid waste," Environmental Science \& Technology, vol. 11, pp. 78-81, 2008.

[6] Z. Song, Y. Lu, L. Yang et al., "Present situation of the development of municipal domestic waste incineration technology," Environmental Sanitation Engineering, vol. 1, pp. 21-24, 2007.

[7] G. Dall, A. Galante, N. Sanna, and K. Miller, "On the integration of leadership in energy and environmental design (LEED) ${ }^{\circledR}$ ND protocol with the energy planning and management tools in Italy: strengths and weaknesses," Energies, vol. 6, no. 11, pp. 5990-6015, 2013.

[8] Q. Xu and H.-L. Xiao, "Experimental study on properties of municipal solid waste incineration bottom ashes," Environmental Engineering, vol. 10, pp. 104-107, 2014, in Chinese.

[9] C. Hall, S. Balogh, and D. Murphy, "What is the minimum EROI that a sustainable society must have?," Energies, vol. 2, no. 1, pp. 25-47, 2009.

[10] P. M. Bierman and C. J. Rosen, "Phosphate and trace metal availability from sewage-sludge incinerator ash," Journal of Environment Quality, vol. 23, no. 4, pp. 822-830, 1994.

[11] S. Ray Sarkar, A. Majumdar, A. Barla et al., "A conjugative study of Typha latifolia for expunge of phyto-available heavy metals in fly ash ameliorated soil," Geoderma, vol. 305, pp. 354-362, 2017.

[12] P. K. Singh, P. Tripathi, S. Dwivedi et al., "Fly-ash augmented soil enhances heavy metal accumulation and phytotoxicity in rice (Oryza sativa L.); a concern for fly-ash amendments in agriculture sector," Plant Growth Regulation, vol. 78, no. 1, pp. 21-30, 2016.

[13] T. Wang, T. Liu, and C. Sun, "Application of MSWI fly ash on acid soil and its effect on the environment," Waste Management, vol. 28, no. 10, pp. 1977-1982, 2008.

[14] Q.-L. Yang, Z.-Z. Wu, J.-L. Chen et al., "Research status of phytoremediation of heavy metals contaminated soil and prospects of water and fertilizer regulating technology," Ecology and Environmental Sciences, vol. 24, no. 6, pp. 1075-1084, 2015, in Chinese.

[15] S.-C. Yang, Y. Zhang, Y.-M. Luo et al., "The influence of cement on the shear strength index of soil mass," Sichuan Architecture, vol. 27, no. 6, pp. 104-105, 2007, in Chinese.

[16] W.-J. Liu, Q.-N. Chen, and L.-J. Zhao, "Research on the strength and disintegration characteristics of the granite residual soil improved with cement," Journal of Hunan University of Science and Technology (Natural Science Edition), vol. 31, no. 1 , pp. 54-59, 2016, in Chinese.

[17] C. Y. Tan, R. Hamid, and K. Mudiono, "Dynamic stress-strain behaviour of steel fiber reinforced high-performance concrete with fly ash," Advances in Civil Engineering, vol. 2012, Article ID 907431, 6 pages, 2012.

[18] S. Mohanty, N. Roy, S. P. Singh, and P. Sihag, "Estimating the strength of stabilized dispersive soil with cement clinker and fly ash," Geotechnical and Geological Engineering, no. 2, pp. 1-12, 2019.

[19] R. K. Sharma and J. Hymavathi, "Effect of fly ash, construction demolition waste and lime on geotechnical characteristics of a clayey soil: a comparative study," Environmental Earth Sciences, vol. 75, no. 5, pp. 1-11, 2016.

[20] S. Cao, "Physical and mechanical properties of fly ash and loess mixing silica gel and their engineering application analysis," M.D. dissertation, Chang'an University, Xi'an, China, 2016.

[21] J. Wang, P. Cao, Y.-L. Zhao et al., "Influence of chemical action of water-soil on soil shear strength," Journal of Central South University, vol. 41, no. 1, pp. 245-250, 2010, in Chinese.

[22] L. I. Min, C. Wang, H. Du et al., "Mechanical properties of oil contaminated saline soil solidified with lime and fly ash," Chinese Journal of Rock Mechanics and Engineering, vol. 36, no. S1, pp. 3578-3586, 2017, in Chinese.

[23] Y. Chi, "The application of fly ash in the expansive soil subgrade reinforcement treatment," Shanxi Science and Technology of Communications, vol. 5, pp. 29-31, 2016, in Chinese.

[24] L. Barton, G. G. Y. Wan, and T. D. Colmer, "Turfgrass (Cynodon dactylon L.) sod production on sandy soils: I. Effects of irrigation and fertiliser regimes on growth and quality," Plant \& Soil, vol. 284, no. 1-2, pp. 129-145, 2006.

[25] L. I. Xing-Xiang and Z. X. Fei, "Study on adaptability of bermudagrass in vegetation concrete," Journal of Yangtze University, vol. 8, pp. 120-123, 2006.

[26] B. R. Phanikumar, "Effect of lime and fly ash on swell, consolidation and shear strength characteristics of expansive clays: a comparative study," Geomechanics and Geoengineering, vol. 4, no. 2, pp. 175-181, 2009.

[27] L. Jia, Y.-P. Zhu, and J.-C. Zhu, "Influencing factors for shear strength of Malan and Lishi compacted loess in Lanzhou," Chinese Journal of Geotechnical Engineering, vol. 36, no. S2, pp. 120-124, 2014, in Chinese.

[28] H. Küpper, F. Küpper, and M. Spiller, "Environmental relevance of heavy metal-substituted chlorophylls using the example of water plants," Journal of Experimental Botany, vol. 47, no. 2, pp. 259-266, 1996. 
[29] J. Wan, H. Xiao, J. He et al., "Analysis of influence factors on the growth of grass-shrub vegetation in highway slope," Highway, vol. 1, pp. 200-204, 2014, in Chinese.

[30] J. S. Li, Q. Xue, P. Wang, H.-Q. Wang, and T.-T. Zhang, "Leaching characteristics of chlorine from municipal solid waste incineration fly ash by up-flow percolation column tests," Environmental Earth Sciences, vol. 75, no. 1, p. 31, 2016.

[31] W. F. Zhao, L. Li, and Y. H. Xiao, "Experimental research of matrix suction of the unsaturated red clay," Advanced Materials Research, vol. 919-921, pp. 835-838, 2014.

[32] Q. Zong, B. O. Feng, H. Cai et al., "Mechanism of riverbank protection by desert riparian vegetation roots in Tarim River basin," Chinese Journal of Rock Mechanics and Engineering, vol. 37, no. 5, pp. 1290-1300, 2018, in Chinese. 


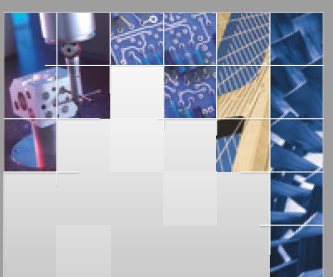

\section{Enfincering}
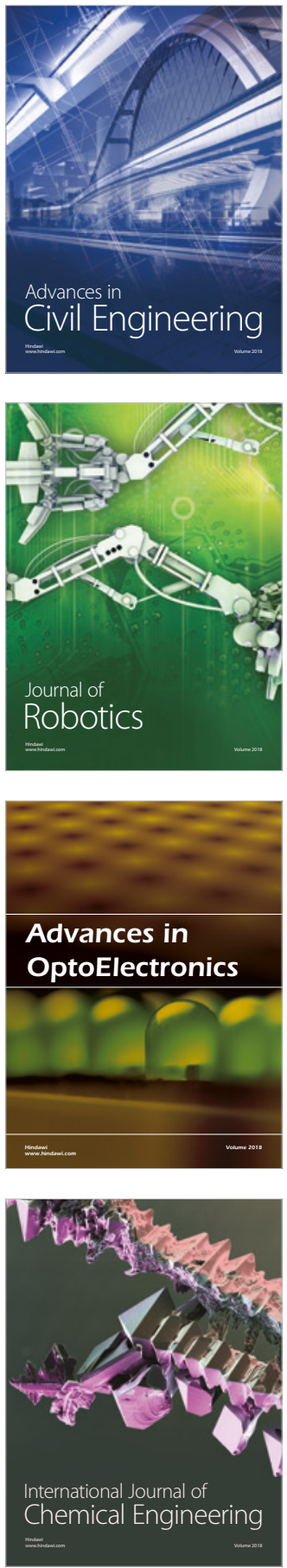

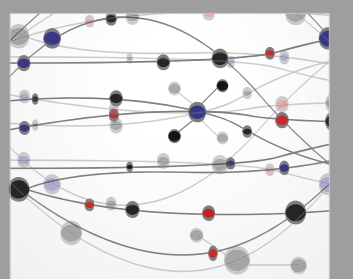

\section{Rotating \\ Machinery}

The Scientific World Journal

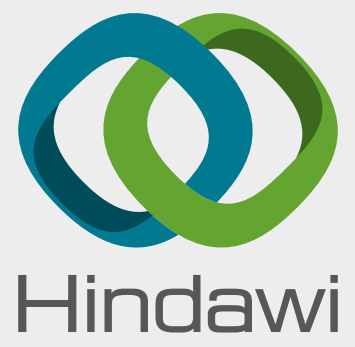

Submit your manuscripts at

www.hindawi.com
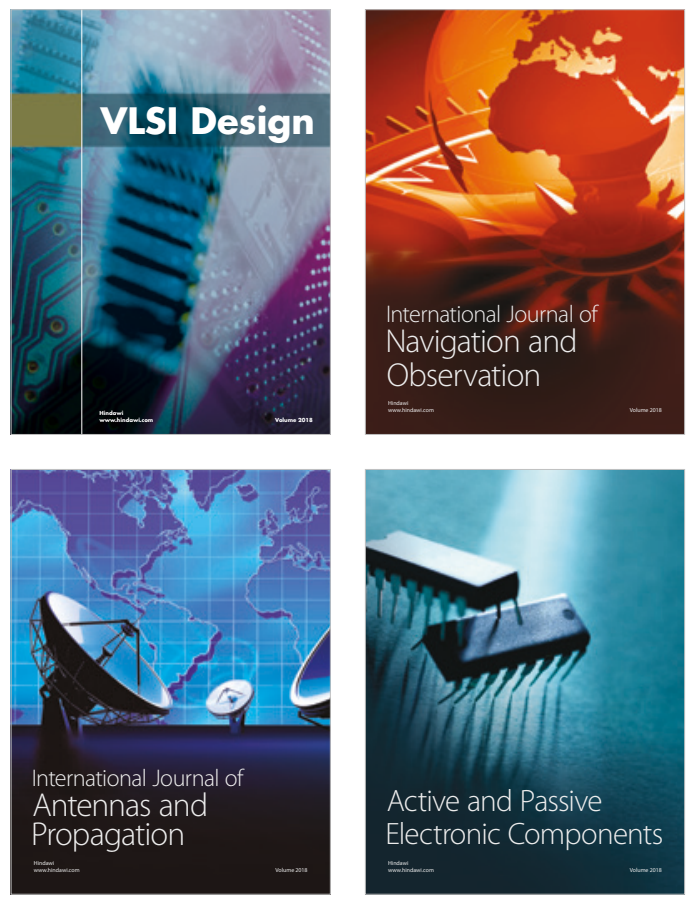
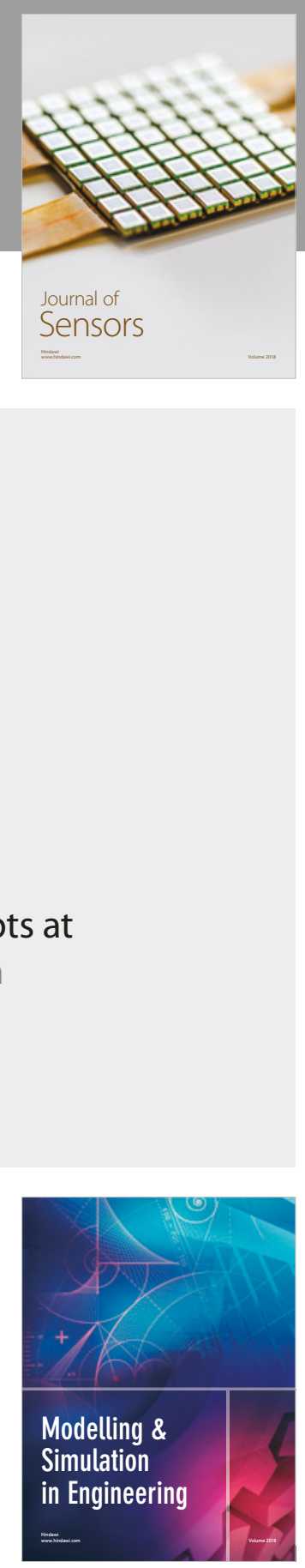

\section{Advances \\ Multimedia}
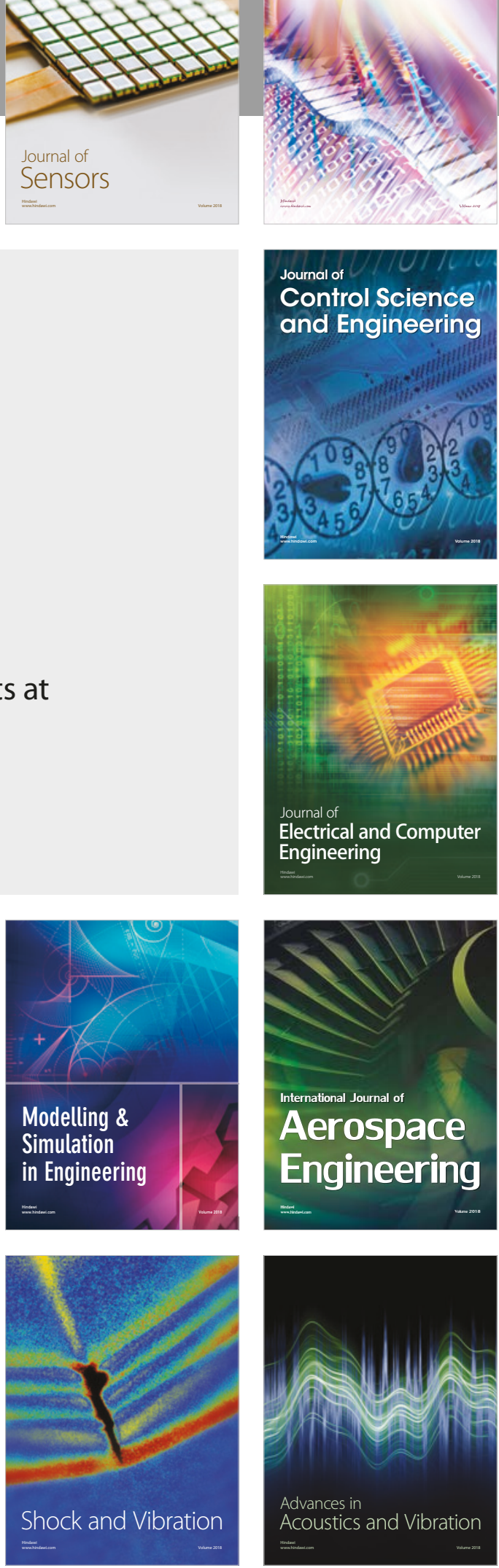